\title{
Digestion of the glycosaminoglycan extracellular matrix by chondroitinase $A B C$ supports retinal ganglion cell dendritic preservation in a rodent model of experimental glaucoma
}

\author{
James R. Tribble ${ }^{1,2^{*}}$ (D) Pete A. Williams², Bruce Caterson ${ }^{3}$, Frank Sengpiel ${ }^{3}$ and James E. Morgan ${ }^{1,4}$
}

\begin{abstract}
Retinal ganglion cell dendritic atrophy is an early feature of glaucoma, and the recovery of retinal ganglion cell dendrites is a viable option for vision improvement in glaucoma. Retinal ganglion cell neurites are surrounded by a specialised glycosaminoglycan extracellular matrix which inhibits dendritic plasticity. Since digestion of the extracellular matrix by chondroitinase $A B C$ has been reported to have neuro-regenerative and neuro-plastic effects within the central nervous system, we explored its potential for dendritic recovery in a rat model of ocular hypertension. Chondroitinase $A B C$ was administrated intravitreally 1 week after ocular hypertension (a time point where dendritic atrophy has already occurred). Retinal ganglion cell dendritic morphology was unaffected by chondroitinase $A B C$ in normal retina. In ocular hypertensive eyes retinal ganglion cells showed significantly decreased dendritic length and area under the Sholl curve with atrophy confined to higher order dendrites. These changes were not observed in chondroitinase $A B C$ injected eyes despite similar total retinal ganglion cell loss (i.e. dendritic protection of surviving retinal ganglion cells). These data suggest that glycosaminoglycan digestion could have a therapeutic role in mitigating the effects of elevated pressure on retinal ganglion cell dendritic structure in glaucoma.
\end{abstract}

Keywords: Retinal ganglion cell, Dendrite, Glaucoma, Neuro-protection, Chondroitinase ABC, Glycosaminoglycan

\section{Main text}

Glaucoma is a common, age-related, neurodegeneration characterised by the progressive atrophy and death of retinal ganglion cells (the output neuron of the retina). Dendritic atrophy is an early feature of neuronal damage, which has been demonstrated in a number of experimental animal glaucoma models [1-3] and offers an attractive therapeutic window in which neuro-regenerative treatments could restore dendritic connectivity and rescue vision. However, the adult central nervous system has

\footnotetext{
* Correspondence: james.tribble@ki.se

${ }^{1}$ School of Optometry and Vision Sciences, Cardiff University, Cardiff, Wales CF24 4HQ, UK

${ }^{2}$ Department of Clinical Neuroscience, Section of Ophthalmology and Vision, St. Erik Eye Hospital, Karolinska Institutet, Polhemsgatan 50, 11282 Stockholm, Sweden

Full list of author information is available at the end of the article
}

limited plasticity, particularly following injury [4]. The extracellular matrix surrounding neurons in the central nervous system plays a dynamic role in synaptic refinement in the critical period, guiding neurite outgrowth before stabilising favourable connections at its closure [5]. It comprises a hyaluronan backbone, proteoglycan lectican family side chains with glycosaminoglycan (GAG) attachments of varying length and composition [6]. Chondroitin sulphate is a common GAG chain that has demonstrated inhibition of plasticity [7]. When removed through enzymatic digestion with chondroitinase $\mathrm{ABC}$, synaptic plasticity has been enhanced in a number of conditions including shifting ocular dominance [8] and striatal re-innervation following nigrostriatal axotomy [9]. We therefore hypothesized that chondroitinase $\mathrm{ABC}$ treatment following glaucomatous degeneration could enable 


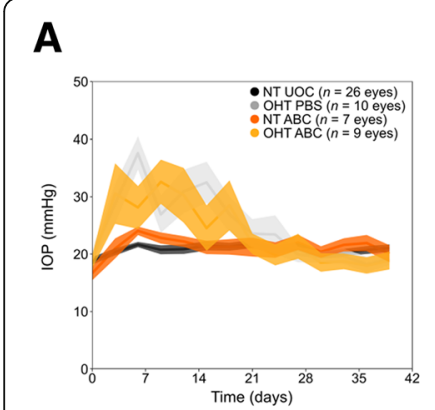

\section{B}

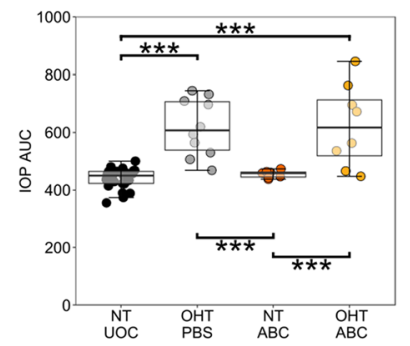

E

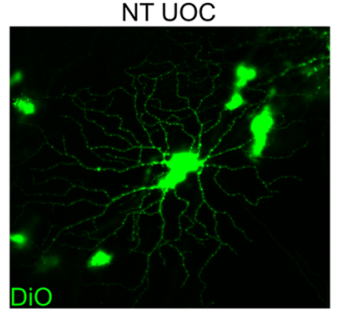

$\mathbf{F}$

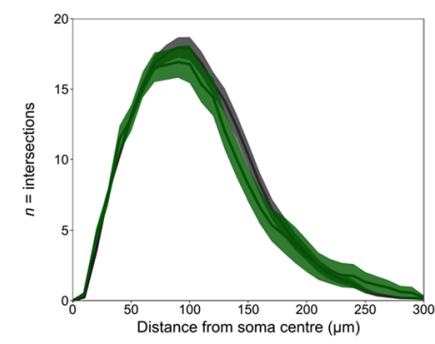

I

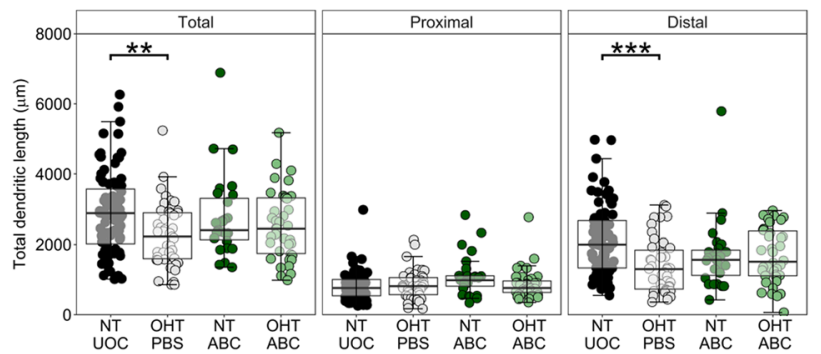

C

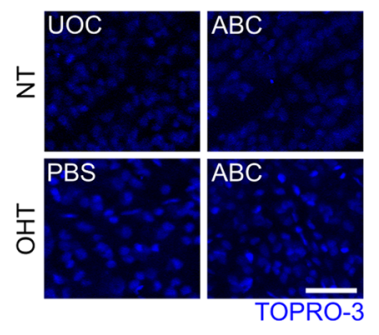

D

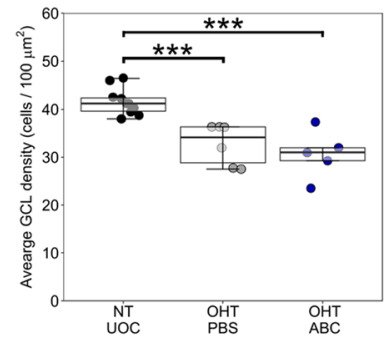

NT ABC

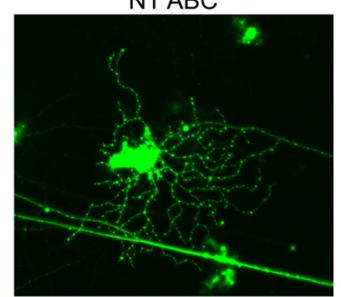

G
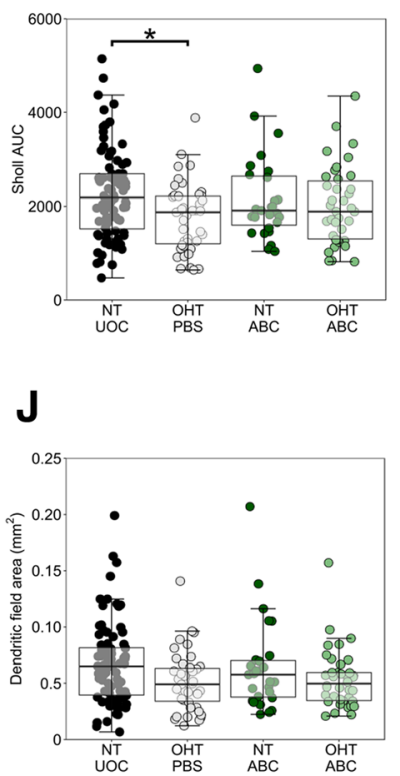

H

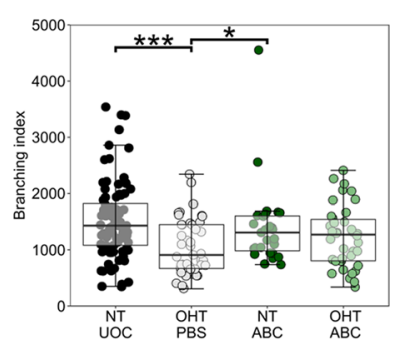

K

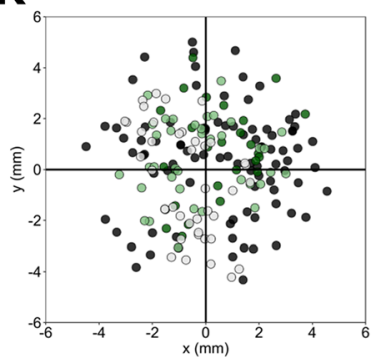

Fig. 1 Chondroitinase ABC protects dendritic architecture following ocular hypertension. a Microbead injections produced 2-3 weeks of raised IOP; average profiles with shaded SD shown. $\mathbf{b}$ The AUC of IOP profiles shows a significantly greater IOP in OHT groups compared to NT UOC. Chondroitinase ABC had no effect on IOP post injection. c Cell loss was assessed by TOPRO-3 counts; example images shown. $\mathbf{d}$ OHT resulted in significant cell loss in the GCL compared to NT UOC; cell loss was not significantly different between OHT groups. e Dendritic morphology was assessed following DiOlistic labelling; example cells from each group shown. $\mathbf{f}$ Sholl profiles demonstrate that chondroitinase ABC injection in NT ABC eyes had no effect on dendritic complexity (left). OHT PBS eyes showed a reduced complexity (statistical values shown in table below plot for NT UOC against OHT PBS) that was rescued by chondroitinase ABC injection (right). Analysis of dendritic morphology revealed a significant reduction in OHT PBS retinal ganglion cells compared to in NT UOC for metrics of Sholl AUC (g), branching index (h), total dendritic length and distal dendritic length (i). $\mathbf{j}$ Dendritic field area was unchanged across groups, indicating reduced density of branches. $\mathbf{k}$ Retinal ganglion cell eccentricity had no effect on dendrite morphology, with cells analyzed across all regions (optic nerve head at $x=0, y=0$; group colors as in F-J). Multivariate regression analysis showed no significant correlation between the distance from optic disc and the outcome variables (Sholl AUC: $R^{2}$ $0.0018, P=0.25$; Sholl BI: $R^{2}-0.0026, P=0.47$; dendritic field area: $R^{2} 0.0993, P=0.01$, total dendritic length: $R^{2} 0.0033, P=0.56$, proximal dendritic length: $R^{2} 0.0087, P=0.10$, and distal dendritic length: $\left.R^{2} 0.0195, P=0.03\right) .{ }^{*}=P<0.05,{ }^{* *}=P<0.01,{ }^{* * *}=P<0.001$. Scale bars $=50 \mu \mathrm{m}$ for $(\mathbf{c}$ ), $100 \mu \mathrm{m}$ for (e). For box plots, center hinge represents the mean and the upper and lower hinges represent the first and third quartiles; whiskers represent 1.5 times the interquartile range 
sufficient retinal plasticity for a re-growth of retinal ganglion cell dendrites.

To assess retinal ganglion cell dendritic architecture, we used a rat inducible model of experimental glaucoma in which para-magnetic microbeads were injected into the anterior chamber, and distributed circumferentially with an externally applied magnet to block aqueous humour drainage and elevate intraocular pressure (IOP). Pressure increases typically last $2-3$ weeks by which point significant retinal ganglion cell dendritic degeneration has occurred $[10,11]$. The left anterior chambers of 19 Brown Norway rats (5 months old) were injected with $30 \mathrm{mg} / \mathrm{ml}\left(4.7 \times 10^{5}\right.$ particles $)$ of para-magnetic polystyrene microspheres $(4.5 \mu \mathrm{m}$ diameter, Kisker Biotechnology, Germany) as described by Samsel et al. [10] generating ocular hypertensive eyes (OHT). The IOP was measured before injection and every 3 days subsequently using a rebound tonometer (Tonolab, Icare, Finland). After the return of the IOP to baseline for the period of 1 week, rats received an intravitreal injection in the OHT eye of either: $3 \mu \mathrm{l}$ chondroitinase $\mathrm{ABC}(10$ $\mathrm{U} / \mathrm{ml}$ in PBS, from Proteus vulgaris, AMS Biotechnology, $\mathrm{UK} ; n=9$, OHT ABC group) or vehicle only (1 M PBS, $n=10$, OHT PBS group). A further 7 rats that were not induced with experimental glaucoma received an intravitreal injection of chondroitinase $\mathrm{ABC}(10 \mathrm{U} / \mathrm{ml}$ in PBS, NT ABC group). All contralateral eyes provided a normotensive un-operated control (NT UOC, $n=26$ ). The effect of treatment was assessed 2 weeks after intravitreal injection, allowing sufficient time for dendritic recovery. We confirmed chondroitinase $\mathrm{ABC}$ action through immunofluorescent labelling of digested chondroitin sulphate GAGs (2B6 antibody [6]) in the ganglion cell layer (GCL; Additional file 1: Figure S1). Eyes were enucleated and retinas flat mounted. Retinal ganglion cells were labelled DiOlistically as described previously [11]. Z-stack confocal images were acquired and dendritic arbours traced manually using NeuronJ [12] in FIJI [13]. TOPRO-3 cell counts were performed on 4 regions of the GCL $\left(100 \mu \mathrm{m}^{2}\right.$ en face area, $1500 \mu \mathrm{m}$ from the optic disc nasally, temporally, superiorly and inferiorly) and averaged. Statistical analysis was performed in R; all tests are one-way ANOVA with Tukey HSD.

OHT eyes demonstrated increased IOPs for 2-3 weeks (mean $\pm \mathrm{SD}=20 \pm 5$ days for OHT PBS, $18 \pm 4$ days for OHT ABC; Fig. 1a) which was significantly greater (IOP area under curve (AUC)) than contralateral controls (NT UOC; $P<0.001$ for OHT PBS, $<0.001$ for OHT ABC; Fig. 1b). Chondroitinase $A B C$ injection alone had no effect on IOP (AUC, $P=0.972$ ). Cell counts revealed a significant decrease in cells in the GCL in both OHT PBS (21\% loss, $P<0.001)$ and OHT ABC-treated eyes (26\% loss, $P<0.001$ ) when compared to contralateral control eyes (Fig. 1c-d). The degree of cell loss was not significantly different between OHT PBS and OHT ABC $(P=0.197)$ indicating comparable IOP induced damage. Analysis of dendritic trees revealed that chondroitinase $A B C$ conferred a significant protection of dendrites in glaucoma (Fig. 1e for representative cells). Sholl analysis (a measure of dendrite frequency at binned distance from the soma, Fig. 1f) revealed a reduced dendritic complexity in OHT PBS as demonstrated by significantly fewer dendrites at distances of $100-160 \mu \mathrm{m}$ from the soma centre $(P<0.05$, see Fig. If for individual values). These Sholl changes were also confirmed when expressed as an AUC $(P=0.014$; Fig. $1 \mathrm{~g})$ and as a branching index (branching events weighted by distance from soma, [14]; $P<0.001$; Fig. 1h). This dendritic atrophy was not observed in OHT ABC (AUC $P=0.578$, branching index $P=0.086$ ). Total dendritic length was decreased in OHT PBS $(P=0.006)$ but not OHT ABC $(P=0.365)$ compared to NT UOC (Fig. 1i). Analysis of individual dendrites revealed that this was confined to the distal dendrites (quaternary and above; $P<0.001$ ) with no changes in proximal dendrites (primary, secondary, tertiary; $P=0.901$ ). Dendritic field area was unchanged between groups; dendrite loss in the absence of filed size changes is indicative of a loss of dendritic density (Fig. 1j). Retinal ganglion cells were sampled evenly across the retina (Fig. $1 \mathrm{k}$ ) and thus the eccentricity did not impact morphological comparisons.

These data demonstrate moderate dendritic preservation in ocular hypertensive eyes following chondroitinase $\mathrm{ABC}$ treatment. Further studies in which single cells are followed longitudinally over time are required to confirm whether this is a protective or regenerative effect. Since it is well established that dendritic loss occurs early during ocular hypertensive insult [3], and as we have previously reported significant dendritic loss in this model after 2 weeks of raised IOP [11] the delayed nature of the treatment in this experimental paradigm is suggestive of a regrowth of dendrites, however, additional time points are required to fully assess this.. Removal of chondroitin sulphate GAG chains may therefore have increased the plastic potential of the retina following injury and may be of therapeutic benefit in glaucoma. In a recent study, the use of Arylsulfatase B to cleave only inhibitory 4-sulphated chondroitin sulphate chains facilitated increased axon outgrowth following optic nerve crush [15]. Therefore a more targeted removal of chondroitin sulphate chains may prove to be more efficacious in glaucoma.

\section{Additional file}

Additional file 1: Figure S1. Chondroitinase $A B C$ action in the $G C L$. Chondroitinase $A B C$ digestion of chondroitin sulphate GAG sidechains leaves 'stubs' that can be targeted by immunofluorescent labelling of cryosections. Digestion to a sulphation residue exposes antibody binding 
sites for 2-B-6 (targeting 4-sulpahted N-acetylgalactosamine). 2-B-6 labelling (green) is clear surrounding cells in the GCL (white; nuclei stained with Hoechst-33,342) in chondroitinase $A B C$ injected eyes $(O H T A B C)$ and is absent in OHT PBS and negative controls sections ( $2^{\circ}$ antibody only). Choroid incubated with chondroitinase $A B C$ ex vivo is used as a positive control, in which 2-B-6 labelling is clear. Scale bar $=50 \mu \mathrm{m}$ for retinal sections, $25 \mu \mathrm{m}$ for choroid section. (TIF $5737 \mathrm{~kb}$ )

\section{Abbreviations}

AUC: Area under the curve; GAG: Glycosaminoglycan; GCL: Ganglion cell layer; IOP: Intraocular pressure; NT UOC: Normotensive un-operated control; OHT ABC: Ocular hypertensive chondroitinase ABC treated; OHT PBS: Ocular hypertensive phosphate buffered saline treated; $\mathrm{OHT}$ : Ocular hypertensive; PBS: Phosphate buffered saline

\section{Acknowledgements}

N/A

\section{Funding}

BB/F016352/1 (BBSRC, U.K.; James E Morgan). Pete Williams is supported by the Karolinska Institutet (in the form of a Board of Research Faculty Funded Career Position).

\section{Availability of data and materials}

All data generated or analysed during this study are included in this published article.

\section{Authors' contributions}

JRT designed and conducted experiments, analyzed data, and wrote the manuscript: PAW analyzed data, wrote the manuscript, provided resources; $B C$ designed experiments, provided resources; FS designed experiments, provided resources; JEM oversaw the project, designed experiments, wrote the manuscript. All authors approved the manuscript.

\section{Authors' information}

JRT is currently a postdoctoral researcher researching neurodegenerative mechanisms in glaucoma at the Karolinska Institutet having previously worked at the School of Optometry and Vision Sciences, Cardiff University. Contact james.tribble@ki.se; Twitter @james_r_tribble.

PAW is an Assistant Professor in Medical Sciences at the Karolinska Institutet researching neurodegenerative and neuroprotective mechanisms. Contact pete.williams@ki.se; Twitter @pete_the_teapot; www.petewilliamslab.com. $\mathrm{BC}$ is an Emeritus Professor at Cardiff University researching degenerative joint diseases and connective tissue proteoglycans. https://www.cardiff.ac.uk/ people/view/81135-caterson-bruce

FS is Head and Professor of Neurosience at Cardiff University studying development, plasticity and visual processing in the primary visual cortex. https://www.cardiff.ac.uk/people/view/61025-sengpiel-frank JEM is Professor of Ophthalmology at Cardiff University and Honorary Consultant Ophthalmologist at the University Hospital of Wales, UK. He also holds an appointment at the School of Optometry and Vision Sciences, Cardiff University. Contact morganje3@cardiff.ac.uk; Twitter @morganje3; https://www.cardiff.ac.uk/people/view/38255-morgan-james-e

\section{Ethics approval}

All experimental procedures were undertaken in accordance with the Association for Research for Vision and Ophthalmology Statement for the Use of Animals in Ophthalmic and Research. The study was in compliance with UK Home Office regulations.

\section{Consent for publication}

N/A

\section{Competing interests}

The authors declare that they have no competing interests.

\section{Publisher's Note}

Springer Nature remains neutral with regard to jurisdictional claims in published maps and institutional affiliations.

\section{Author details}

${ }^{1}$ School of Optometry and Vision Sciences, Cardiff University, Cardiff, Wales CF24 4HQ, UK. ${ }^{2}$ Department of Clinical Neuroscience, Section of Ophthalmology and Vision, St. Erik Eye Hospital, Karolinska Institutet, Polhemsgatan 50, 11282 Stockholm, Sweden. ${ }^{3}$ School of Biosciences, Cardiff University, Cardiff, Wales CF10 3AX, UK. ${ }^{4}$ School of Medicine, Cardiff University, Cardiff, Wales CF14 4XW, UK.

Received: 17 September 2018 Accepted: 7 November 2018

Published online: 21 November 2018

\section{References}

1. Williams PA, Howell GR, Barbay JM, Braine CE, Sousa GL, John SWM, Morgan JE. Retinal ganglion cell dendritic atrophy in DBA/2J glaucoma. PLoS One. 2013;8(8):e72282.

2. Weber AJ, Kaufman PL, Hubbard WC. Morphology of single ganglion cells in the glaucomatous primate retina. Invest Ophthalmol Vis Sci. 1998;39:230420.

3. Chong R, Martin K. Retinal ganglion cell dendrites and glaucoma: a case of missing the wood for the trees? Expert Rev Ophthalmol. 2014;9:149-52.

4. Cregg JM, DePaul MA, Filous AR, Lang BT, Tran A, Silver J. Functional regeneration beyond the glial scar. Exp Neurol. 2014;253:197-207.

5. Wang D, Fawcett J. The perineuronal net and the control of CNS plasticity. Cell Tissue Res. 2012;349:147-60.

6. Caterson B. Fell-Muir lecture: chondroitin sulphate glycosaminoglycans: fun for some and confusion for others. Int J Exp Pathol. 2012;93:1-10.

7. Orlando C, Ster J, Gerber U, Fawcett JW, Raineteau O. Perisynaptic chondroitin sulfate proteoglycans restrict structural plasticity in an integrindependent manner. J Neurosci. 2012;32:18009-17 18017a.

8. Pizzorusso T, Medini P, Berardi N, Chierzi S, Fawcett JW, Maffei L. Reactivation of ocular dominance plasticity in the adult visual cortex. Science. 2002;298:1248-51.

9. Moon LDF, Asher RA, Rhodes KE, Fawcett JW. Regeneration of CNS axons back to their target following treatment of adult rat brain with chondroitinase ABC. Nat Neurosci. 2001:4:465-6.

10. Samsel PA, Kisiswa L, Erichsen JT, Cross SD, Morgan JE. A novel method for the induction of experimental Glaucoma using magnetic microspheres. Invest Ophthalmol Vis Sci. 2011;52:1671-5.

11. Williams PA, Tribble JR, Pepper KW, Cross SD, Morgan BP, Morgan JE, John SWM, Howell GR. Inhibition of the classical pathway of the complement cascade prevents early dendritic and synaptic degeneration in glaucoma. Mol Neurodegener. 2016;11:26

12. Meijering E, Jacob M, Sarria JC, Steiner P, Hirling H, Unser M. Design and validation of a tool for neurite tracing and analysis in fluorescence microscopy images. Cytometry A. 2004;58:167-76.

13. Schindelin J, Arganda-Carreras I, Frise E, Kaynig V, Longair M, Pietzsch T, Preibisch S, Rueden C, Saalfeld S, Schmid B, et al. Fiji: an open-source platform for biological-image analysis. Nat Methods. 2012;9:676-82.

14. Garcia-Segura LM, Perez-Marquez J. A new mathematical function to evaluate neuronal morphology using the Sholl analysis. J Neurosci Methods. 2014;226:103-9.

15. Pearson CS, Mencio CP, Barber AC, Martin KR, Geller HM. Identification of a critical sulfation in chondroitin that inhibits axonal regeneration. Elife. 2018;7:e37139.

\section{Ready to submit your research? Choose BMC and benefit from:}

- fast, convenient online submission

- thorough peer review by experienced researchers in your field

- rapid publication on acceptance

- support for research data, including large and complex data types

- gold Open Access which fosters wider collaboration and increased citations

- maximum visibility for your research: over $100 \mathrm{M}$ website views per year

At BMC, research is always in progress.

Learn more biomedcentral.com/submissions 